\title{
Anemia due to Disorder of Nucleotide Metabolism
}

National Cancer Institute

\section{Source}

National Cancer Institute. Anemia due to Disorder of Nucleotide Metabolism. NCI

Thesaurus. Code C35469.

A group of hemolytic anemias that result from either the deficiency or overproduction of several enzymes involved in metabolizing nucleotides. 